\title{
UMA RETROSPECTIVA DO ESTUDO DA REJEIÇÃO DE LIMITAÇÕES COMO PONTO CENTRAL DA BRICOLAGEM EMPREENDEDORA
}

Arnaldo Di Petta ${ }^{1}$

\footnotetext{
${ }^{1}$ Programa de Pós Graduação em Administração - PPGA / Universidade Nove de Julho
} 


\title{
UMA RETROSPECTIVA DO ESTUDO DA REJEIÇÃO DE LIMITAÇÕES COMO PONTO CENTRAL DA BRICOLAGEM EMPREENDEDORA
}

\begin{abstract}
Resumo:
A partir do conceito de bricolagem, proposto por Lévi-Strauss (1966), Baker e Nelson (2005) desenvolveram a teoria da bricolagem empreendedora, tendo incluído o conceito de rejeição de limitações como construto central. A presente revisão de literatura mostra que o artigo que deu origem a esta teoria já foi citado mais de 2.900 vezes em trabalhos de diferentes áreas. Entretanto, tomando deste total os 118 trabalhos mais relevantes de acordo com o número de citações recebidas, observa-se que poucos são aqueles que aceitaram a proposta dos autores de estudar mais profundamente a rejeição de limitações. Como resultado, ficou evidente a necessidade de se estudar mais o conceito de rejeição de limitações por parte dos empreendedores e, assim, identificar seus aspectos comportamentais. Ao sintetizar os pontos que foram levantados até agora neste particular, e propor uma maneira de integrá-los, este artigo contribui para a construção da teoria comportamental da bricolagem empreendedora.
\end{abstract}

Palavras-chave: Empreendedorismo. Bricolagem empreendedora. Rejeição de limitações.

\section{$1 \quad$ Introdução}

O interesse pelo estudo do empreendedorismo tem se intensificado nos últimos anos e, assim, surgiram várias novas perspectivas teóricas para explicar as ações e a lógica inerentes ao comportamento empreendedor (Fisher, 2012). De uma maneira geral, estas novas perspectivas vêm sendo corroboradas pela constatação de que o empreendedorismo se constrói com processos dinâmicos conduzidos pelos empreendedores, os quais criam perspectivas futuras e continuamente se adaptam de acordo com suas experiências anteriores (Garud \& Giuliani, 2013). Além desta constatação, outros pesquisadores afirmam que o processo de empreendedorismo é formado pela recombinação de elementos sociais e materiais (Stinchfield, Nelson, \& Wood, 2012; F. Welter, Baker, Audretsch, \& Gartner, 2017).

Uma das novas perspectivas teóricas que contrastam com a perspectiva tradicional, na qual o empreendedorismo era visto como um processo linear de descoberta, avaliação e exploração de oportunidades (Shane \& Venkataraman, 2000), é a da bricolagem empreendedora, que estuda o empreendedor que faz algo com o pouco que tem às mãos, rejeitando limitações impostas pelo ambiente (Baker \& Nelson, 2005). Em seus estudos, Baker e Nelson (2005) constataram que muitos empreendimentos são caracterizados, dentre as adversidades, pela forte restrição de recursos. Isso levou esses autores a formularem a teoria da bricolagem empreendedora. A partir da visão original de bricolagem (Lévi-Strauss, 1966), cujas três características principais são ter recursos à mão (resources at hand), recombinar os recursos para novos propósitos (recombination of resources for new purposes) e 'dar um jeito' para fazer acontecer (making do), Baker e Nelson (2005) acrescentaram a característica de rejeitar limitações (refuse to enact limitations).

Baker e Nelson (2005) argumentam que um dos pontos fundamentais da bricolagem empreendedora é que os empreendedores são capazes de fazer alguma coisa com muito pouco, explorando ideias ou até mesmo recombinando materiais e recursos que são rejeitados ou 
ignorados por outros empreendedores. Além disso, observaram que os empreendedores que se utilizam da bricolagem empreendedora rejeitam limitações impostas pelo ambiente em que atuam. Esta rejeição pode ser vista como um desrespeito a interpretações comumente aceitas quanto a práticas, definições, padrões e recursos, bem como quanto a limitações relativas a esses próprios elementos. Além disso, recusando-se a aceitar limitações em relação a muitos padrões e regulamentos, e ativamente experimentando novas coisas em várias áreas que não conhecem, os empreendedores não veem as regras como limitantes (Fisher, 2012). Baker e Nelson (2005) enfatizam o tema da rejeição de limitações como uma recusa empreendedora de ter sua atuação restringida por limitações (ex.: de recursos) impostas por ambientes institucionais e ou políticos. Dessa forma, em vez de somente rejeitar as limitações, os empreendedores resistem às restrições ambientais impostas a eles e ao mesmo tempo experimentam soluções, trabalham com resultados e acumulam experiências.

Vale destacar que, logo no início de seu artigo, Baker e Nelson (2005) explicitam que a rejeição de limitações é um ponto central da contribuição trazida por eles na teoria da bricolagem empreendedora (p. 329). Reconhecem também, ao final do seu trabalho, que o estudo da bricolagem empreendedora abre a oportunidade para o exercício de capacidades organizacionais e comportamentos, tais como criatividade, improviso e habilidades sociais. Entretanto, o entendimento detalhado da relação entre a bricolagem empreendedora e estas capacidades e comportamentos permanece talvez como a parte mais fraca do modelo apresentado por eles (p. 360), carecendo de estudos empíricos adicionais (p. 361).

Assim, dada a centralidade do conceito da rejeição de limitações na bricolagem empreendedora e também a necessidade de entender melhor sua relação com esta teoria, o presente trabalho busca responder as seguintes perguntas: o que tem sido pesquisado e discutido a respeito da rejeição de limitações no contexto da bricolagem empreendedora? Nestes quinze anos, desde a publicação do artigo original, que contribuições surgiram para aprofundar o estudo da rejeição de limitações? Como integrá-las em pesquisas atuais?

Em resposta a essas perguntas, com uma revisão da literatura pertinente, este artigo levanta nos últimos 15 anos o que foi publicado sobre rejeição de limitações. Assim, será possível identificar oportunidades para novos estudos que contribuam para o desenvolvimento do tema. Para isso, após esta introdução, a próxima seção apresenta o referencial teórico sobre o empreendedorismo, a bricolagem empreendedora e seus domínios principais. Na seção de métodos, são detalhados os passos e os critérios usados para a revisão de literatura e, na sequência, a seção de resultados apresenta a análise da literatura revisada. A seção de conclusões trata das implicações dos resultados trazidos por este trabalho, além de suas limitações. $\mathrm{O}$ artigo é finalizado com recomendações e sugestões para pesquisas futuras.

\section{Referencial Teórico}

Esta seção tem por objetivo apresentar um breve levantamento histórico sobre o empreendedorismo mostrando a diversidade de estudos a seu respeito. Em suma, a proposta é mostrar a origem do termo e os desdobramentos dos conceitos que inicialmente mostravam o empreendedorismo como um processo linear de descoberta, avaliação e exploração de oportunidades e que, ao longo do tempo, passaram também a considerar a importância do indivíduo no processo empreendedor. Nesse contexto, explicita-se a teoria da bricolagem empreendedora, destacando os domínios propostos por seus autores. 


\subsection{Empreendedorismo}

O empreendedorismo tem sido estudado de diferentes maneiras em diferentes campos (Kuckertz \& Mandl, 2016), contudo ainda sofre por não ter uma definição clara a respeito de seus construtos da mesma forma como ainda falta um modelo que possa representá-lo de maneira ampla e consistente (Van Burg \& Romme, 2014). Há mais de trinta anos pesquisadores já generalizavam conclusões a partir de estudos específicos, formando uma visão não aplicável do que seria empreendedorismo (Cooper \& Dunkelberg, 1987). Entretanto, o empreendedorismo tem um grande potencial para a construção de novos conhecimentos, suportado pelos contextos social, econômico, ambiental e de negócios, sendo tempo de aprofundar o conhecimento com rigor cientifico (Nassif, 2019).

Ao longo do tempo, as pesquisas têm avançado em diferentes direções gerando uma diversidade de estudos que na visão de alguns pode sufocar o crescimento do campo de estudo do empreendedorismo (Gartner, 2007; Lopes, Almeida, \& Lima, 2019), mas que também pode ser necessária para seu desenvolvimento (Zahra \& Wright, 2011). Neste artigo, para efeito de referência, mencionam-se a perspectiva tradicional (Shane \& Venkataraman, 2000) e também duas das novas perspectivas teóricas para o estudo do empreendedorismo, a effectuation (Sarasvathy, 2001) e a bricolagem empreendedora (Baker \& Nelson, 2005). Além de serem as mais citadas dentre as novas perspectivas, estas duas obras oferecem explicações de caráter geral sobre o empreendedorismo (Fisher, 2012).

Na perspectiva tradicional (Shane \& Venkataraman, 2000), o empreendedorismo seria um campo de pesquisa do porquê, quando e como oportunidades para a criação de bens e serviços passam a existir, ou porque, quando e como algumas pessoas e não outras, descobrem e exploram essas oportunidades e porque, quando e como diferentes modos de ação são usados para explorar oportunidades empresariais (Shane \& Venkataraman, 2000). Alargando o campo de estudo do empreendedorismo, a effectuation e a bricolagem empreendedora surgiram para explicar as ações e a lógica inerentes ao comportamento do empreendedor (Fisher, 2012).

A effectuation e a bricolagem empreendedora levam em consideração o papel do indivíduo, apontando na direção da formação de um consenso em torno da ideia central de que o empreendedorismo é um processo que depende tanto de oportunidades como de indivíduos (Shane, 2012). Da mesma forma, estas duas novas teorias oferecem modelos comportamentais que refletem o que os empreendedores fazem na prática e como eles exploram as oportunidades (C. Welter, Mauer, \& Wuebker, 2016). A effectuation envolve a identificação de oportunidades em um ambiente altamente incerto (Sarasvathy, 2001), enquanto que a bricolagem empreendedora envolve empreendedores em um ambiente de recursos escassos, que rejeitam as limitações e fazem acontecer com o pouco que está às mãos (Baker \& Nelson, 2005).

\subsection{Bricolagem Empreendedora}

A teoria da bricolagem, proposta por Lévi-Strauss (1966), não apresentava uma definição específica para uma determinada área de estudo (Stinchfield, Nelson, \& Wood, 2013). Assim sendo, Baker \& Nelson (2005) tomaram proveito de seus conceitos para aplicá-los ao estudo do empreendedorismo. A partir de uma pesquisa com empreendedores que enfrentavam ambientes com recursos escassos, Baker \& Nelson (2005) definiram a bricolagem empreendedora como dar um jeito, combinando recursos limitados disponíveis à mão, com novos propósitos e gerando soluções para novos problemas ou novas oportunidades. Na mesma pesquisa, identificaram que os bricoleurs, aqueles que se utilizam da bricolagem 
empreendedora, rejeitavam as limitações impostas pelo ambiente e, assim, experimentavam e encontravam soluções diferentes para as situações enfrentadas por eles. As empresas estudadas desconsideravam as práticas ou recursos usualmente preferidos pelas demais empresas e, em vez disso, buscavam novas soluções à medida que encontravam resultados de suas primeiras tentativas.

Alguns estudos identificaram que este tipo de resultados, gerados pela bricolagem empreendedora, seriam de qualidade inferior (Duymedjian \& Rüling, 2010) ou mesmo que não seriam a solução ideal, sendo tachados de incompletos e até mesmo ineficientes, ainda que fossem reconhecidos como a única solução razoável sob determinadas situações (Desa \& Basu, 2013). Em ambientes de escassez de recursos, os bricoleurs são levados a direcionar sua atenção para recursos disponíveis e assim, tentativamente explorar estes recursos para alcançar a solução do problema enfrentado. Na visão de Baker \& Nelson (2005), estes recursos estariam disponíveis por serem muito baratos ou mesmo porque nada custariam, uma vez que as outras empresas os desprezavam por serem ultrapassados ou até mesmo sem utilidade. Os bricoleurs recombinam os recursos considerando e rejeitando suas limitações, frequentemente usando-os de maneiras para as quais não foram inicialmente concebidos. Estas tentativas fazem da bricolagem empreendedora uma abordagem prática e experiencial na qual os empresários arranjam e rearranjam os recursos para se ajustar às mudanças no ambiente ou no mercado em que estão inseridos (Steffens, Senyard, \& Baker, 2009).

Ainda no estudo de Baker \& Nelson (2005), eles notaram que as empresas pesquisadas formaram dois padrões em relação a busca de oportunidades por meio da utilização de recursos disponíveis, e a estes dois padrões chamaram de bricolagem seletiva e bricolagem paralela. As empresas pesquisadas, que na visão dos autores usavam o padrão seletivo, eram aquelas que adotaram a bricolagem por um determinado período de tempo, geralmente até seu crescimento. Neste momento, elas deixaram de usar a bricolagem em todos os seus domínios, isto é, os aspectos do funcionamento de uma empresa, e optaram por não mais serem limitadas em suas demandas e recursos, descaracterizando-se assim de estarem usando a bricolagem empreendedora (Baker \& Nelson, 2005: p. 349).

Em outro padrão identificado, a bricolagem paralela, caracterizava-se pela realização de mais de um projeto ao mesmo tempo, mas principalmente por fazer uso da bricolagem de maneira repetida e consistente em vários domínios verificados nas empresas estudadas. Foi observado que as empresas que usaram a bricolagem paralela, criaram algo relevante a partir de muito pouco em diferentes aspectos do funcionamento de uma empresa, ou seja, nos cinco domínios identificados pelos autores: insumos físicos, mão-de-obra, habilidades, clientes e ambiente institucional (Baker \& Nelson, 2005: p. 348).

$\mathrm{Na}$ visão de Baker e Nelson (2005), os cinco domínios nos quais a bricolagem foi empregada pelas empresas que se utilizaram da bricolagem paralela foram evidenciados pelas seguintes características: i) estas empresas criaram novos serviços a partir de insumos físicos (inputs) que outras empresas rejeitaram; ii) elas extraíram o trabalho, ou mão de obra, (labor) de clientes não pagos ou de simples observadores da situação vivida; iii) tiraram a melhor habilidade (skills) daqueles que eram considerados desqualificados em outras empresas; iv) as empresas que usaram da bricolagem empreendedora transformaram em clientes (customer/markets), pessoas cujos poucos recursos as mantiveram longe de comprar de 
empresas convencionais, e v) elas prestaram serviços nas sombras e/ou lacunas do ambiente institucional (institutional and regulatory environment) (p. 349).

A Figura 1 mostra que a rejeição de limitações, agindo em cada um dos cinco domínios, cria espaço para apresentar soluções que, de outro modo, pareceriam inadmissíveis (p. 349). Assim é possível entender porque a rejeição de limitações, nas palavras de Baker e Nelson (2005), é o ponto central da bricolagem empreendedora e ainda carece de ser estudado mais profundamente para identificar aspectos comportamentais deste tipo de empreendedor. A identificação destes aspectos contribuirá para o desenvolvimento de uma teoria comportamental da bricolagem empreendedora (Davidsson, Baker, \& Senyard, 2017).

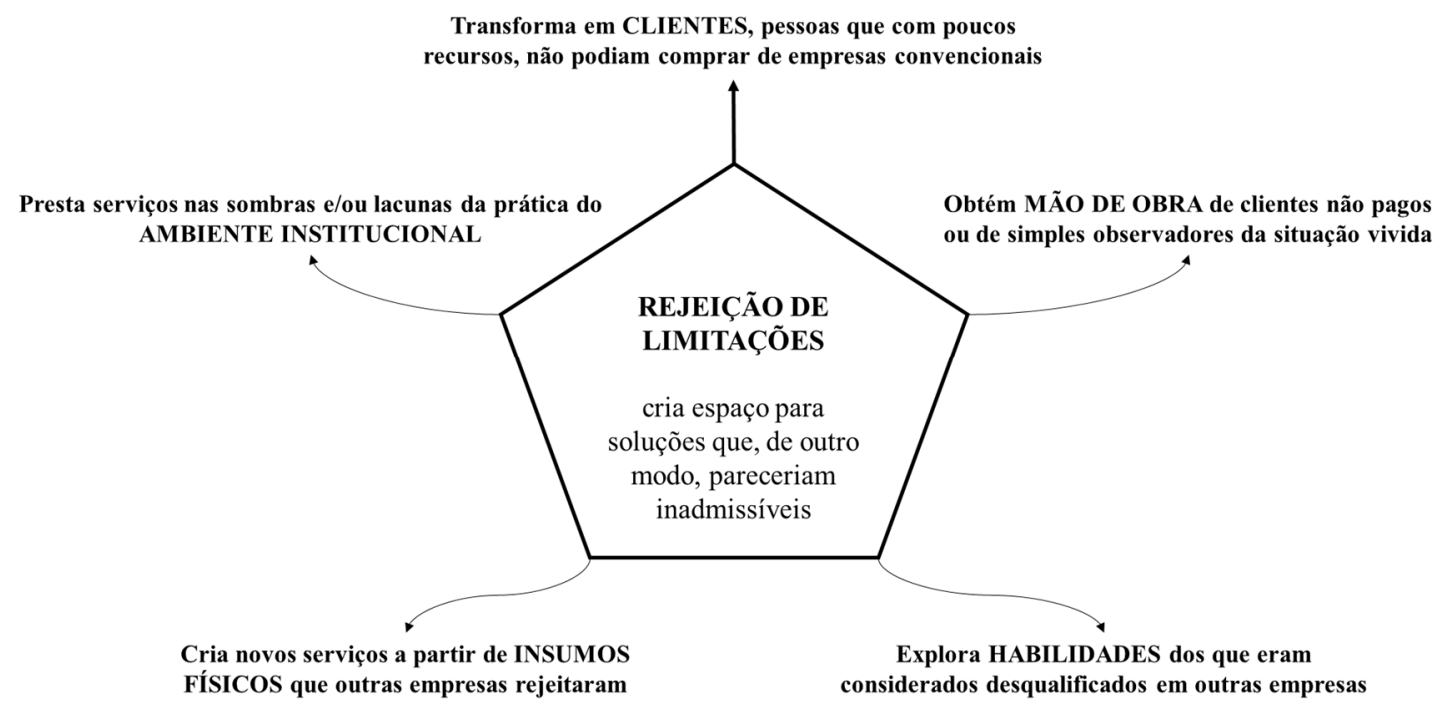

Figura 1: centralidade da rejeição de limitações em relação aos 5 domínios na bricolagem empreendedora Fonte: preparado pelo autor com base em (Baker \& Nelson, 2005)

Na Figura 1, preparada de acordo com os achados no estudo de Baker \& Nelson (2005), apresenta-se a rejeição de limitações ao centro, observando como ela se expressa na prática, criando espaço para que o bricoleur rejeite a limitação de considerar como inúteis, insumos físicos desprezados por outras empresas. Para ele, estes insumos rejeitados podem ser a base para a oferta de novos produtos ou serviços. Da mesma forma, o estudo mostrou que os bricoleurs rejeitaram o rótulo de desqualificados, aplicado por outras empresas a seus antigos empregados. Pelo contrário, os bricoleurs tomaram proveito das habilidades destes empregados desprezados, para solucionar problemas que se apresentavam no dia-a-dia.

A rejeição de limitações verificou-se também com a atuação dos bricoleurs em situações onde as leis ou mesmo o ambiente regulatório dificultava o estabelecimento de um negócio. A não aceitação de determinados limites foi fundamental para que eles aproveitassem as oportunidades de negócio. Além disso, a rejeição de limitações impostas pela formalidade levou os bricoleurs estudados por Baker e Nelson (2005) a tomarem gratuitamente, proveito do trabalho e das contribuições de pessoas envolvidas na solução do problema em questão, fossem eles clientes ou simples observadores da situação. Finalmente, destaca-se que todas estas rejeições levaram os bricoleurs, oferecerem a consumidores menos abastados, produtos simples, porém eficientes para a solução de suas necessidades. 


\section{$3 \quad$ Método}

A revisão da literatura é uma parte importante em qualquer pesquisa, pois é a partir dela que será desenvolvida a base de conhecimento para responder à questão de pesquisa proposta (Tranfield, Denyer, \& Smart, 2003). Ela pode ser sistemática, baseando-se em um processo claro e definido, de tal forma que possa ser repetido (Ridley, 2012) e neste contexto, a revisão de literatura aplicada para este estudo buscou limitar qualquer tipo de viés, com o objetivo geral de produzir um resumo científico de evidências na área específica do conhecimento (Petticrew \& Roberts, 2008), no caso, a rejeição de limitações como ponto central da bricolagem empreendedora.

A pesquisa bibliográfica utilizada neste trabalho foi conduzida a partir da base de dados Scholar Google, que inicialmente permitiu observar que o artigo de Baker \& Nelson (2005) desde sua publicação na Revista Administrative Science Quarterly em Setembro de 2005, até Novembro de 2019, foi citado mais de 2.900 vezes, sendo a evolução visualizada na Figura 2.

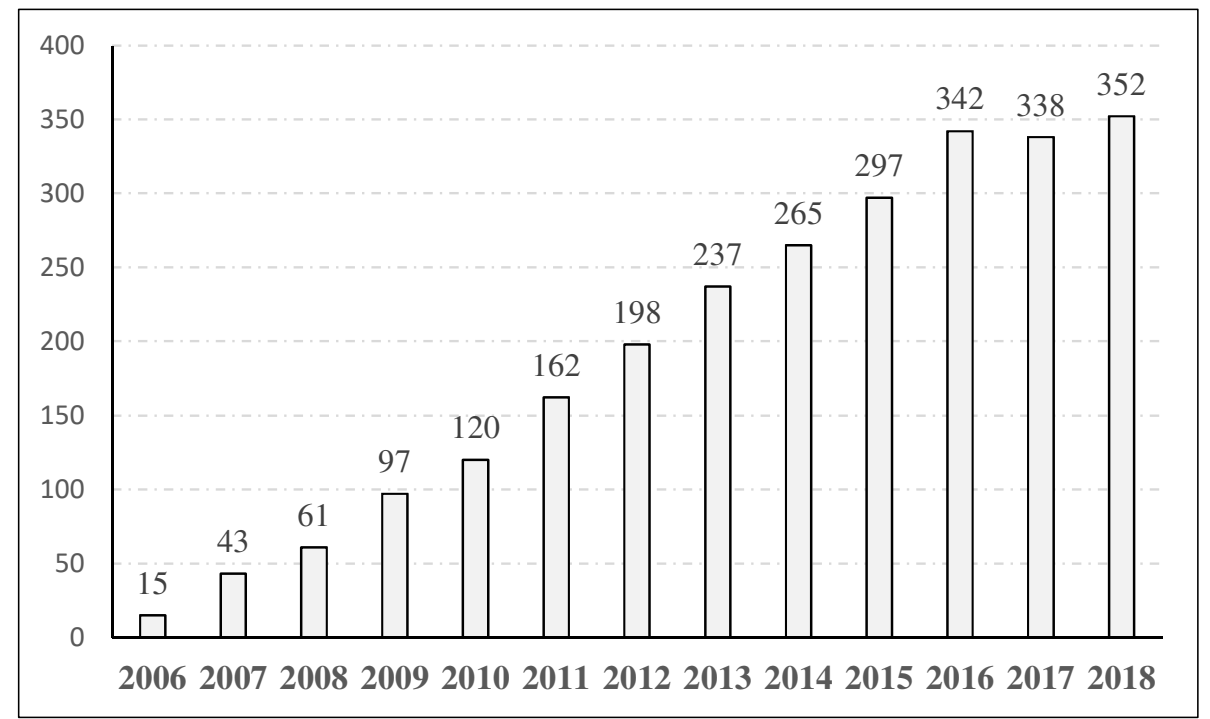

Figura 2: Progressão do número de citações do artigo de Baker e Nelson (2005)

Fonte: preparado pelo autor com base no Scholar Google (Nov/2019)

Com o objetivo de levantar a relevância dos trabalhos que citaram o artigo em análise, foi preparada uma relação de trabalhos que citaram Baker e Nelson (2005) e que alcançaram mais de 200 citações em todos os tempos, resultando em 69 obras. Destas 69, foram eliminadas três que, talvez por um erro de sistema, não faziam menção a Baker e Nelson (2005) e também um livro, fora do escopo desta revisão. Para cobrir também obras relevantes que citaram o artigo em estudos mais recentes, porém que por esta razão ainda não tiveram um número expressivo de citações, foi feita uma busca adicional de 35 trabalhos que citaram o artigo nos últimos cinco anos, desde 2014. Vale destacar que três trabalhos recentes já superaram as 200 citações e outros nove já superaram as 100 citações, o que mostra a importância desta segunda busca. Ao final desta primeira fase de levantamento, chegou-se a uma lista com 100 artigos que tiveram seus resumos lidos e as referências a Baker e Nelson (2005) escrutinadas com a ferramenta de busca (Ctrl F) em cada um dos textos. 
De maneira complementar ao levantamento inicial, considerando que o objetivo do presente trabalho é identificar e discutir o que tem sido pesquisado e discutido a respeito da rejeição de limitações no contexto da bricolagem empreendedora, em um segundo momento, foi utilizada a ferramenta Publish or Perish (PoP). Por meio do PoP, foram buscados todos os artigos também na base Scholar Google com a expressão em Inglês "refusal to enact limitations", exatamente a mesma usada por Baker e Nelson (2005) para se referir a rejeição de limitações. Desta filtragem, surgiram 38 trabalhos, dos quais apenas 18 se enquadravam como artigos relevantes e que também foram objeto da leitura de seus resumos e do escrutínio das referências a Baker e Nelson (2005) com a ferramenta de busca (Ctrl F).

Por fim, após as duas fases do levantamento e segundo os critérios de seleção aplicados, o total de artigos relevantes que citavam Baker e Nelson (2005) chegou a 118, representando 4,0\% do total de citações que o artigo recebeu desde sua publicação até Novembro de 2019.

\section{$4 \quad$ Resultados}

Tomando os 118 artigos selecionados de acordo com os critérios de relevância mencionados, foi feita uma primeira análise para identificar quantos destes artigos estabeleciam um diálogo com Baker e Nelson (2005), ou seja, se aprofundavam de alguma forma em relação aos conceitos apresentados pelos autores. O propósito desta primeira análise foi identificar artigos que contribuíssem para fortalecer o modelo proposto por Baker e Nelson (2005), o qual sugere relação entre a bricolagem empreendedora e as capacidades organizacionais e comportamentos tais como criatividade, improviso e habilidades sociais. O resultado desta primeira análise mostrou que 42 artigos traziam apenas uma citação genérica ao artigo de Baker e Nelson (2005), mencionando somente o conceito da bricolagem empreendedora e não especificando nenhum dos domínios, isto é, nenhum dos aspectos do funcionamento de uma empresa, encontrados por eles. Por esta razão, estes 42 artigos foram desprezados nesta análise por não se enquadrarem aos objetivos deste trabalho, ou seja, aprofundar o estudo da rejeição das limitações.

Em relação aos 76 artigos restantes, foi possível classificá-los de acordo com os cinco domínios utilizados por Baker e Nelson (2005) durante seus estudos e assim verificar qual dos domínios é o mais mencionado pelos autores que citam o artigo original. Ao final desta classificação identificou-se que metade, ou seja, 38 artigos citam a bricolagem empreendedora sob a perspectiva de insumos físicos (inputs). Outros 33, citam a bricolagem empreendedora em relação a habilidades (skills), 3 artigos se referem ao domínio clientes (customer), 2 artigos tocam o ambiente institucional (institutional environment) e nenhum dos artigos analisados traz uma visão da mão-de-obra (labor) em relação à bricolagem empreendedora. $\mathrm{O}$ resultado desta segunda análise mostrou quase que uma polarização de artigos entre os domínios de insumos físicos e habilidades, evidenciando a escassez de artigos que citam a bricolagem empreendedora e sua relação com os clientes, com a mão-de-obra e com o ambiente institucional.

Uma terceira análise feita nos mesmos 76 artigos, apontou que 56 deles, mesmo sendo específicos em relação aos domínios, citam Baker e Nelson (2005) de maneira superficial, isto é, sem diálogo e sem aprofundamento em relação aos conceitos propostos pelos autores, principalmente o da rejeição de limitações. Por fim, dos 20 artigos remanescentes, 16 tocam o domínio de habilidades, três dialogam com o domínio de insumos físicos e um, conversa sobre o ambiente institucional. Ou seja, de um total inicial de 118 artigos, a presente revisão encontrou 
apenas 20 artigos que trouxeram contribuições para aprofundar o estudo da rejeição das limitações. Este resultado inicial já corrobora a perspectiva de Welter et al. (2016) de que, até o momento, o indivíduo empreendedor não vem recebendo a devida atenção na literatura sobre a bricolagem empreendedora.

Feita esta análise inicial e para facilitar a resposta à pergunta de pesquisa sobre quais foram as contribuições trazidas nestes quinze anos que permitem aprofundar o estudo da rejeição das limitações e assim apoiar a construção mais completa da teoria da bricolagem empreendedora, os 20 artigos revisados em maior profundidade foram classificados em três grupos. O primeiro deles, considerando que o empreendedorismo é fundamentalmente baseado em ações (Moroz \& Hindle, 2012), referem-se a contribuições no estudo da ação dos empreendedores. O segundo grupo, reflete as contribuições referentes ao comportamento do empreendedor, uma vez que o empreendedorismo é essencialmente pessoal (Baum, Frese, \& Baron, 2014). Finalmente, o terceiro grupo mostra as contribuições que propõem o estudo da bricolagem empreendedora como um processo, uma vez que conceber um fenômeno em termos de processo, pode representar uma oportunidade de fazer com que o estudo da disciplina do empreendedorismo possa avançar, além de propiciar o compartilhamento do conhecimento e da prática empreendedora (Kuratko, Morris, \& Schindehutte, 2015). A Figura 3 sintetiza esta classificação, abrindo oportunidade para a discussão de cada um dos grupos.

\begin{tabular}{|c|c|c|}
\hline GRUPO 1 & GRUPO 2 & GRUPO 3 \\
\hline $\begin{array}{l}\text { AÇÃO DO EMPREENDEDOR } \\
\text { (como) }\end{array}$ & $\begin{array}{l}\text { COMPORTAMENTO } \\
\text { DO EMPREENDEDOR }\end{array}$ & PROCESSO \\
\hline $\begin{array}{l}\text { - } \text { Alvarez, Barney \& Anderson, } \\
\text { 2013; } \\
\text { - Azmat, Ferdous \& Couchman, } \\
\text { 2015; } \\
\text { - } \text { Cornelissen \& Clarke, 2010; } \\
\text { - } \text { Di Domenico, Haugh \& Tracey } \\
\text { 2010; } \\
\text { - Frese \& Gielnik, 2014; } \\
\text { - } \text { Gartner \& Baker, 2010; } \\
\text { - Mair \& Marti, 2009; } \\
\text { - } \text { Rindova, Barry \& Ketchen Jr, } \\
\text { 2009; } \\
\text { - Sunduramurthy, Zheng, } \\
\text { Musteen, Francis \& Rhyne, } \\
\text { 2016; } \\
\text { - Townsend, Hunt, McMullen \& } \\
\text { - Sarasvathy, 2018; } \\
\text { - Upson, Damaraju, Anderson, \& } \\
\text { Barney, 2017; } \\
\text { - Valliere \& Gegenhuber, 2014; } \\
\text { - Wu, Liu \& Zhang, 2017. }\end{array}$ & $\begin{array}{l}\text { - Fayolle, 2013; } \\
\text { - Fisher, 2012; } \\
\text { - Halme, Lindeman, \& Linna, } \\
\text { 2012; } \\
\text { - Hmieleski \& Corbett, } 2008 .\end{array}$ & $\begin{array}{l}\text { - Alvarez \& Barney, 2007; } \\
\text { - Bechky \& Okhuysen, 2011. } \\
\text { - Sarasvathy \& Venkataraman, } \\
\text { 2011; }\end{array}$ \\
\hline
\end{tabular}

Figura 3: Lista dos artigos revisados em maior profundidade

Fonte: preparado pelo autor com base no Scholar Google (Nov/2019)

Inicialmente, no grupo 1, o dos artigos que têm em comum as contribuições para o estudo das ações dos empreendedores, vale destacar o modelo geral da psicologia do empreendedorismo (Frese \& Gielnik, 2014) que mostra a centralidade das características de 
ação dos empreendedores, seus antecedentes e a influência que estas características de ação exercem sobre o sucesso do empreendedor. Recomendam a realização de pesquisas futuras concentrando-se em resultados mais subjetivos, como satisfação com a vida, tensão ou equilíbrio entre trabalho e vida pessoal o que na perspectiva da bricolagem empreendedora, tocaria mais profundamente o empreendedor bricoleur. Outro artigo neste grupo 1 e que faz uso da psicologia para tratar da criação ou da descoberta de oportunidades empreendedoras é o que trata da importância das redes de relacionamento (Upson, Damaraju, Anderson, \& Barney, 2017). Aplicado à bricolagem empreendedora, é possível pesquisar e discutir as ações, rejeições e reações dos bricoleurs tanto na exploração de novos produtos como na geração de demandas por estes produtos.

Oferecer uma abordagem pragmática e conceitual para unir a literatura cognitiva e a literatura institucional sobre empreendedorismo e também enfatizar a abordagem de sensemaking na qual a ideia de um novo empreendimento é imaginada, refinada e justificada para outros (Cornelissen \& Clarke, 2010) é a contribuição deste artigo ao corpo teórico do grupo 1. Os autores reconhecem que existe muito pouca pesquisa sobre empreendedorismo que tenha fornecido uma especificação teórica de quando e como os empreendedores usam comparações analógicas ou metafóricas específicas para raciocinar sobre um empreendimento em uma indústria nova e desconhecida. Ampliando o foco da pesquisa no empreendedorismo, (Rindova, Barry, \& Ketchen Jr, 2009) trazem a quebra de restrições para os empreendedores e para os outros como a criação de novas possibilidades. Acreditam que o exame cuidadoso e sistemático do papel da paixão no empreendedorismo pode levar os estudiosos a compreender por que e como os indivíduos dão seus primeiros passos no caminho do empreendedorismo.

Um destaque especial ao artigo que busca relacionar as teorias institucionais com o empreendedorismo e que traz a visão de que pouco se sabe a respeito de 'como' os empreendedores constroem novas instituições. As formas pelas quais atores menos poderosos, com recursos limitados, tentaram transformar e desinstitucionalizar regras que impedem o desenvolvimento social e econômico, receberam, até agora, pouca atenção (Mair \& Marti, 2009). Também dentro do grupo 1, uma revisão de literatura de Townsend, Hunt, McMullen, \& Sarasvathy (2018), apresenta uma agenda de pesquisa em vários níveis para explorar a ação empreendedora sob condições de ambiguidade, complexidade e incerteza. Empresários assumem um alto grau de agência tanto respondendo às restrições do meio ambiente como no enactment, ou seja, na concepção de vários mecanismos de organização. Dentre várias propostas de pesquisas futuras, os autores sugerem considerar como a ambiguidade e a complexidade influenciam a ação empreendedora.

A descrição das teorias do empreendedorismo que tratam da criação ou descoberta de oportunidades e o entendimento das implicações destas teorias para as ações dos empreendedores mostram que a rejeição, em caráter geral, é citada como elemento para a criação de oportunidades (Alvarez \& Barney, 2007). Estes autores valorizam a ação e destacam que os empreendedores tomam decisões de maneira indutiva e ao final sugerem: Como a ação dos empreendedores cria oportunidades? Outro artigo no grupo 1 é aquele que mesmo focando o empreendedorismo social, procura contribuir para a extração, geração e extensão de novas teorias, utilizando a lente conceitual da bricolagem (Di Domenico, Haugh, \& Tracey, 2010). Este artigo vai além da restrição de recursos imposta por ambientes institucionais e/ou políticos, estendendo o conceito de refusal a uma perspectiva de resistência às limitações do ambiente, 
chamando-o de 'segundo construto' da bricolagem empreendedora. Mais um artigo analisado dentro deste grupo, traz uma perspectiva a respeito da rejeição de limitações. Colocando a bricolagem empreendedora em um contexto pós-moderno mais amplo e comparando-a a dois estilos musicais, o jazz e o hip hop (Valliere \& Gegenhuber, 2014), o artigo identifica outras implicações inexploradas para a criação de valor empreendedor. Valoriza o desafio das limitações percebidas em vez de concebidas (enacted) e ilustra como os empreendedores pósmodernos podem explorar sua sanção social para a destruição criativa. Para eles, a rejeição de limitações é um dos princípios da criação de valor.

Três artigos procuram contribuir na direção da ação do empreendedor, trazendo perspectivas distintas em relação ao conceito inicial de bricolagem. Um deles propõe que as empresas usem a bricolagem até certo nível, isso para não impedirem o desenvolvimento de abordagens inovadoras (Wu, Liu, \& Zhang, 2017). Entretanto, esta contribuição, de certa forma, assemelha-se à definição da bricolagem seletiva, o que desqualificaria a empresa como usuária da bricolagem empreendedora. Outro artigo propõe a adição de dois novos construtos à bricolagem social, ou seja, a inovação contínua e o empoderamento dos desfavorecidos (Azmat, Ferdous, \& Couchman, 2015). Esta proposta, voltada à bricolagem social, também é específica para contextos onde os recursos do próprio mercado são limitados, sendo desta forma bastante particular para determinada situação. Finalmente, outra contribuição que, de alguma maneira, desvirtua o conceito original da bricolagem empreendedora é aquela que sugere a utilização de determinado padrão engenhoso para a replicação de iniciativas de caráter social, também dentro a bricolagem social (Sunduramurthy, Zheng, Musteen, Francis, \& Rhyne, 2016).

O último artigo, enquadrado dentro do grupo 1, fornece um framework teórico de como os indivíduos geram recursos para buscar oportunidades e vice-versa. Aponta situações em que os recursos à mão, levam a oportunidades e onde a imaginação reconfigura recursos e oportunidades em negócios viáveis (Gartner \& Baker, 2010). Neste contexto, os autores mostram que aqueles envolvidos em bricolagem podem testar ativamente as limitações relacionadas a definições de recursos, padrões profissionais e éticos, bem como regulamentações legais. Os casos apresentados por este artigo podem nos permitir ver como esses empreendedores veem suas circunstâncias e, então, ajudam a prestar atenção a como as próprias circunstâncias dos empreendedores podem ser oportunidades que esperam ser criadas. Um desafio interessante é a exploração de três grandes questões envolvidas na pesquisa em empreendedorismo: o que acontece quando os empreendedores atuam, por que atuam e como atuam. E esta oportunidade é contrastada com a observação de que os artigos que tratam da bricolagem social têm dado atenção ao indivíduo empreendedor. Se compreendermos a bricolagem empreendedora como resposta comportamental à incerteza em geral, pode haver aplicações para campos além do empreendedorismo (C. Welter et al., 2016).

Analisando o grupo 2, que contém os artigos que apontam na direção de pesquisar o comportamento do empreendedor, observamos que o exame do efeito moderador da autoeficácia empreendedora no relacionamento com o comportamento de improviso do fundadores, sua performance e sua satisfação no trabalho, pode levar ao estudo da tendência dos bricoleurs de assumirem muitas tarefas não relacionadas às suas responsabilidades (Hmieleski \& Corbett, 2008). Observa-se também que a incorporação da bricolagem e seus comportamentos empreendedores relacionados, pode fortalecer o conteúdo da educação empreendedora (Fayolle, 2013). Outro dos artigos bastante citados e que se enquadra no grupo 2, examina de 
maneira crítica como diferentes perspectivas teóricas na pesquisa de empreendedorismo se traduzem em comportamento individual, e se tal comportamento é evidente na criação e desenvolvimento de novos empreendimentos (Fisher, 2012). Apesar de não reconhecer explicitamente o refusal como um dos elementos centrais da definição da bricolagem empreendedora, o artigo de Fisher (2012) reconhece a necessidade de mais estudos que considerem as implicações comportamentais nas novas teorias. Finalmente neste grupo de artigos, ao definir a bricolagem intraempreendedora, caracterizada pelo agrupamento criativo de recursos escassos em grandes empresas, ilustrando como isso ajuda os inovadores a rejeitar superar as restrições organizacionais e a mobilizar recursos internos e externos (Halme, Lindeman, \& Linna, 2012), reforçam a importância do networking e destacam que estudos empíricos anteriores não examinaram o aspecto mental da bricolagem, mas exploraram a bricolagem no nível das ações.

Dentre os artigos classificados no grupo 3, aqueles que têm em comum a perspectiva de estudar a bricolagem empreendedora como um processo, ao defender que as oportunidades criadas não existem até que elas sejam 'enacted', ou seja, concebidas e efetivamente implantadas, Alvarez, Barney, \& Anderson (2013), sugerem pesquisas futuras baseadas em processos usados para formar e explorar oportunidades, alinhado ao conceito de enactment. Segundo Weick (1979), o comportamento de um indivíduo cria o ambiente dentro do qual ele mesmo se comporta e as ações precedem interpretações e interpretações dessas ações precedem novas ações. Este grupo 3 traz também um artigo que explora as organizações que regularmente e com sucesso, respondem à surpresa, estando preparadas para mudar seu trabalho à medida que suas circunstâncias mudam (Bechky \& Okhuysen, 2011). Estes autores expressam que Baker e Nelson (2005) prestaram pouca atenção conceitual aos processos pelos quais as organizações constroem a capacidade social e cognitiva de se engajar na bricolagem e acreditam que o desenvolvimento e o uso de recursos sócio-cognitivos explicariam como a bricolagem permite a capacidade de resposta à surpresa. $\mathrm{O}$ último artigo neste grupo 3 , é aquele que apresenta sete questões abertas que apoiariam os pesquisadores no estudo do empreendedorismo como um método. Assim, o ensino do empreendedorismo, não apenas a empreendedores, mas a todos, transmitiria uma habilidade necessária e útil e uma importante maneira de raciocinar sobre o mundo (Sarasvathy \& Venkataraman, 2011). Ao sugerir a bricolagem empreendedora como um mecanismo que poderia ser ensinado nos cursos de graduação, os autores reconhecem a necessidade de se ampliar o estudo de como os empreendedores tomam decisões e respectivas ações.

\section{Conclusões}

Apesar de conhecida e muito citada, a teoria da bricolagem empreendedora parece ainda não ter desafiado outros pesquisadores a contribuírem para seu desenvolvimento. Isto porque uma primeira conclusão a partir da presente revisão de literatura, é a predominância de artigos que citam a bricolagem empreendedora apenas como uma referência genérica, principalmente na perspectiva de reação à escassez de recursos.

Poucos foram os artigos encontrados que se aprofundaram na discussão dos demais conceitos da bricolagem empreendedora, estabelecendo um diálogo com o artigo original de Baker e Nelson (2005). E aqueles que o fizeram, não trouxeram uma contribuição objetiva na direção de fortalecer o modelo apresentado por eles, sobretudo no aspecto comportamental. 
Observou-se também pouca discussão em relação à bricolagem empreendedora e o domínio do ambiente institucional, o que abre oportunidade para o estudo da rejeição às limitações institucionais, por exemplo.

De qualquer forma, para responder à pergunta 'que contribuições surgiram para aprofundar o estudo da rejeição de limitações', a análise de 20 artigos relevantes e pertinentes gerou a separação em três grupos de temas. O primeiro deles, composto por treze artigos, converge na direção do estudo das ações do empreendedor para a rejeição de limitações (Moroz \& Hindle, 2012). Apesar de ter duas contribuições mais voltadas à bricolagem social (Azmat et al., 2015; Sunduramurthy et al., 2016) e uma que desvirtuaria o princípio da bricolagem empreendedora (Wu et al., 2017), é possível resumir as principais contribuições deste grupo na proposição de pesquisas que explorem a rejeição de limitações como criadora de oportunidades e agregação de valor (Alvarez \& Barney, 2007; Cornelissen \& Clarke, 2010; Di Domenico et al., 2010; Gartner \& Baker, 2010; Valliere \& Gegenhuber, 2014). Outras contribuições seriam as ações do empreendedor sob a perspectiva da psicologia (Frese \& Gielnik, 2014; Upson et al., 2017). Alinhadas a estas últimas, o estudo da paixão do empreendedor (Rindova et al., 2009) e as ações dos empreendedores em um contexto de ambiguidade, complexidade e incerteza (Townsend et al., 2018). Finalmente, destaque para a sugestão de estudar como as rejeições levam à criação de novas instituições (Mair \& Marti, 2009).

O segundo grupo, composto por quatro artigos, aborda temas comportamentais do empreendedor em relação à rejeição de limitações (Baum et al., 2014). Suas contribuições são mais no aspecto de valorizar a necessidade de estudar o comportamento do empreendedor (Fayolle, 2013; Fisher, 2012; Halme et al., 2012), todos estes autores alinhados a ênfase de que, até o momento, o indivíduo empreendedor não vem recebendo a devida atenção na literatura sobre a bricolagem empreendedora (C. Welter et al., 2016). Talvez a contribuição mais específica neste grupo é a de examinar o efeito moderador da auto-eficácia empreendedora no relacionamento com o comportamento de improviso do fundadores, sua performance e sua satisfação no trabalho (Hmieleski \& Corbett, 2008).

Por fim, o terceiro grupo composto por três artigos e que aponta na direção de estudar a bricolagem empreendedora como um processo (Kuratko et al., 2015), tem a perspectiva de ensinar a todos uma maneira diferente de ver o mundo (Sarasvathy \& Venkataraman, 2011). Além disso, permitiria estudar os processos usados para formar e explorar oportunidades (Alvarez \& Barney, 2007) e como estar preparados para responder às surpresas (Bechky \& Okhuysen, 2011).

Diante da variedade de contribuições levantadas, é difícil encontrar somente uma resposta à pergunta 'como integrar as contribuições trazidas nos últimos quinze anos'. Desde uma perspectiva ampla, é possível observar que existe uma boa oportunidade de explorar o comportamento do empreendedor no contexto da bricolagem empreendedora. É essencial identificar casos de empreendedores que rejeitaram as limitações, em particular aquelas determinadas pelas instituições, dando maior ênfase ao comportamento do indivíduo em vez de sua capacidade de gerenciar a escassez de recursos, pode ser a chave para definir um processo que reflita suas ações tomadas ao longo do tempo, dentro do contexto no qual eles estão inseridos. Outra oportunidade é tomar a perspectiva de aprofundar o estudo da bricolagem empreendedora sob a perspectiva de um processo que facilite o estudo de um possível padrão e a disseminação do ensino das características do bricoleur. De qualquer forma, o estudo do 
empreendedorismo e em particular da bricolagem empreendedora ainda tem um longo caminho pela frente, sendo o seu dinamismo, a sua variedade de definições e conceitos, a dificuldade da demarcação dos seus limites e a sua multidisciplinariedade, as limitações mais conhecidas, também aplicáveis a este trabalho.

\section{Referências}

Alvarez, S. A., \& Barney, J. B. (2007). Discovery and creation: Alternative theories of entrepreneurial action. Strategic entrepreneurship journal, 1(1-2), 11-26.

Alvarez, S. A., Barney, J. B., \& Anderson, P. (2013). Forming and exploiting opportunities: The implications of discovery and creation processes for entrepreneurial and organizational research. Organization Science, 24(1), 301-317.

Baker, T., \& Nelson, R. E. (2005). Creating Something from Nothing: Resource Construction through Entrepreneurial Bricolage. Administrative Science Quarterly, 50(3), 329-366.

Bechky, B. A., \& Okhuysen, G. A. (2011). Expecting the unexpected? How SWAT officers and film crews handle surprises. Academy of Management Journal, 54(2), 239-261.

Cooper, A. C., \& Dunkelberg, W. C. (1987). Entrepreneurial research: Old questions, new answers and methodological issues. American Journal of Small Business, 11(3), 11-24.

Cornelissen, J. P., \& Clarke, J. S. (2010). Imagining and rationalizing opportunities: Inductive reasoning and the creation and justification of new ventures. Academy of Management Review, 35(4), 539-557.

Davidsson, P., Baker, T., \& Senyard, J. M. (2017). A measure of entrepreneurial bricolage behavior. International Journal of Entrepreneurial Behavior \& Research, 23(1), 114-135.

Desa, G., \& Basu, S. (2013). Optimization or bricolage? Overcoming resource constraints in global social entrepreneurship. Strategic Entrepreneurship Journal, 7(1), 26-49.

Duymedjian, R., \& Rüling, C.-C. (2010). Towards a foundation of bricolage in organization and management theory. Organization Studies, 31(2), 133-151.

Fayolle, A. (2013). Personal views on the future of entrepreneurship education. Entrepreneurship \& Regional Development, 25(7-8), 692-701.

Fisher, G. (2012). Effectuation, causation, and bricolage: A behavioral comparison of emerging theories in entrepreneurship research. Entrepreneurship theory and practice, 36(5), 10191051.

Frese, M., \& Gielnik, M. M. (2014). The psychology of entrepreneurship. Annu. Rev. Organ. Psychol. Organ. Behav., 1(1), 413-438.

Gartner, W. B. (2007). Entrepreneurial narrative and a science of the imagination. Journal of Business Venturing, 22(5), 613-627.

Gartner, W. B., \& Baker, T. (2010). A plausible history and exploration of Stevenson's definition of entrepreneurship. Frontiers of entrepreneurship research, 30(4), 2.

Garud, R., \& Giuliani, A. P. (2013). A narrative perspective on entrepreneurial opportunities. Academy of Management Review, 38(1), 157-160.

Halme, M., Lindeman, S., \& Linna, P. (2012). Innovation for inclusive business: Intrapreneurial bricolage in multinational corporations. Journal of Management Studies, 49(4), 743-784.

Hmieleski, K. M., \& Corbett, A. C. (2008). The contrasting interaction effects of improvisational behavior with entrepreneurial self-efficacy on new venture performance and entrepreneur work satisfaction. Journal of business venturing, 23(4), 482-496. 
Kuckertz, A., \& Mandl, C. (2016). Capturing the complexity and ambiguity of academic fields: Determining consensual definitions for small business research, entrepreneurship and their shared interface. In Complexity in Entrepreneurship, Innovation and Technology Research (p. 417-438). Springer.

Lévi-Strauss, C. (1966). The savage mind, Chicago (The University of Chicago Press) 1966.

Mair, J., \& Marti, I. (2009). Entrepreneurship in and around institutional voids: A case study from Bangladesh. Journal of business venturing, 24(5), 419-435.

Petticrew, M., \& Roberts, H. (2008). Systematic reviews in the social sciences: A practical guide. John Wiley \& Sons.

Ridley, D. (2012). The literature review: A step-by-step guide for students (2a.). Recuperado de https://books.google.com.br/books

Rindova, V., Barry, D., \& Ketchen Jr, D. J. (2009). Entrepreneuring as emancipation. Academy of management review, 34(3), 477-491.

Sarasvathy, S. D. (2001). Causation and effectuation: Toward a theoretical shift from economic inevitability to entrepreneurial contingency. Academy of management Review, 26(2), 243-263.

Sarasvathy, S. D., \& Venkataraman, S. (2011). Entrepreneurship as method: Open questions for an entrepreneurial future. Entrepreneurship theory and practice, 35(1), 113-135.

Shane, S. (2012). Reflections on the 2010 AMR decade award: Delivering on the promise of entrepreneurship as a field of research. Academy of Management Review, 37(1), 10-20.

Shane, S., \& Venkataraman, S. (2000). The promise of entrepreneurship as a field of research. Academy of management review, 25(1), 217-226.

Steffens, P. R., Senyard, J. M., \& Baker, T. (2009). Linking resource acquisition and development processes to resource-based advantage: Bricolage and the resource-based view.

Stinchfield, B. T., Nelson, R. E., \& Wood, M. S. (2013). Learning from Levi-Strauss' Legacy: Art, Craft, Engineering, Bricolage, and Brokerage in Entrepreneurship. Entrepreneurship theory and practice, 37(4), 889-921.

Townsend, D. M., Hunt, R. A., McMullen, J. S., \& Sarasvathy, S. D. (2018). Uncertainty, knowledge problems, and entrepreneurial action. Academy of Management Annals, 12(2), 659-687.

Tranfield, D., Denyer, D., \& Smart, P. (2003). Towards a methodology for developing evidence-informed management knowledge by means of systematic review. British journal of management, 14(3), 207-222.

Upson, J. W., Damaraju, N. L., Anderson, J. R., \& Barney, J. B. (2017). Strategic networks of discovery and creation entrepreneurs. European Management Journal, 35(2), 198-210.

Valliere, D., \& Gegenhuber, T. (2014). Entrepreneurial remixing: Bricolage and postmodern resources. The international journal of entrepreneurship and innovation, 15(1), 5-15.

Van Burg, E., \& Romme, A. G. L. (2014). Creating the future together: Toward a framework for research synthesis in entrepreneurship. Entrepreneurship Theory and Practice, 38(2), 369-397.

Welter, C., Mauer, R., \& Wuebker, R. J. (2016). Bridging behavioral models and theoretical concepts: Effectuation and bricolage in the opportunity creation framework. Strategic Entrepreneurship Journal, 10(1), 5-20. 
Welter, F., Baker, T., Audretsch, D. B., \& Gartner, W. B. (2017). Everyday entrepreneurshipa call for entrepreneurship research to embrace entrepreneurial diversity. SAGE Publications Sage CA: Los Angeles, CA.

Zahra, S. A., \& Wright, M. (2011). Entrepreneurship's next act. Academy of Management Perspectives, 25(4), 67-83. 